\title{
Aligned Nanofiber-Guided Bone Regeneration Barrier Incorporated with Equine Bone-Derived Hydroxyapatite for Alveolar Bone Regeneration
}

\author{
Jae Woon Lim ${ }^{1}$, Kyoung Je Jang ${ }^{2}$, Hyunmok Son ${ }^{1}$, Sangbae Park ${ }^{1}{ }^{\circledR}$, Jae Eun Kim ${ }^{1}$, Hong Bae Kim ${ }^{1}$, \\ Hoon Seonwoo ${ }^{3}$, Yun Hoon Choung ${ }^{4,5}$, Myung Chul Lee ${ }^{1, *(\mathbb{D})}$ and Jong Hoon Chung ${ }^{1,6, *(\mathbb{D})}$ \\ 1 Department of Biosystems Engineering, Seoul National University, Seoul 08826, Korea; \\ jwlim1130@snu.ac.kr (J.W.L.); shmking@snu.ac.kr (H.S.); sb92park@snu.ac.kr (S.P.); Je6740@snu.ac.kr (J.E.K.); \\ ser21@hanmail.net (H.B.K.) \\ 2 Division of Agro-System Engineering, Gyeongsang National University, Jinju 52828, Korea; \\ trudwp@gmail.com \\ 3 Department of Industrial Machinery Engineering, College of Life Science and Natural Resources, \\ Sunchon National University, Sunchon 57922, Korea; uhun906@scnu.ac.kr \\ 4 Department of Otolaryngology, Ajou University School of Medicine, Suwon 16499, Korea; yhc@ajou.ac.kr \\ 5 Bk21 Plus Research Center for Biomedical Sciences, Ajou University Graduate School of Medicine, \\ Suwon 16499, Korea \\ 6 Research Institute of Agriculture and Life Sciences, Seoul National University, Seoul 08826, Korea \\ * Correspondence: josephmyungchul@gmail.com (M.C.L.); jchung@snu.ac.kr (J.H.C.)
}

check for updates

Citation: Lim, J.W.; Jang, K.J.; Son, H.; Park, S.; Kim, J.E.; Kim, H.B.; Seonwoo, H.; Choung, Y.H.; Lee, M.C.; Chung, J.H. Aligned Nanofiber-Guided Bone Regeneration Barrier Incorporated with Equine Bone-Derived Hydroxyapatite for Alveolar Bone Regeneration. Polymers 2021, 13, 60. https://dx.doi.org/10.3390/polym13 010060

Received: 24 November 2020 Accepted: 22 December 2020 Published: 25 December 2020

Publisher's Note: MDPI stays neutral with regard to jurisdictional claims in published maps and institutional affiliations.

Copyright: (c) 2020 by the authors. Licensee MDPI, Basel, Switzerland. This article is an open access article distributed under the terms and conditions of the Creative Commons Attribution (CC BY) license (https: / / creativecommons.org / licenses/by/4.0/).

\begin{abstract}
Post-surgery failure of dental implants due to alveolar bone loss is currently critical, disturbing the quality of life of senior dental patients. To overcome this problem, bioceramic or bone graft material is loaded into the defect. However, connective tissue invasion instead of osteogenic tissue limits bone tissue regeneration. The guided bone regeneration concept was adapted to solve this problem and still has room for improvements, such as biochemical similarity or oriented structure. In this article, an aligned electrospun-guided bone regeneration barrier with xenograft equine bonederived nano hydroxyapatite (EBNH-RB) was fabricated by electrospinning EBNH/PCL solution on high-speed rotating drum collector and fiber characterization, viability and differentiation enhancing properties of mesenchymal dental pulp stem cell on the barrier was determined. EBNH-RB showed biochemical and structural similarity to natural bone tissue electron microscopy image analysis and $\mathrm{x}$-ray diffractometer analysis, and had a significantly better effect in promoting osteogenesis based on the increased bioceramic content by promoting cell viability, calcium deposition and osteogenic marker expression, suggesting that they can be successfully applied to regenerate alveolar bone as a guided bone regeneration barrier.
\end{abstract}

Keywords: osteogenesis; equine bone; hydroxyapatite; nanofiber; regeneration barrier

\section{Introduction}

The human organs and tissues are developed in aligned matter. Tendon [1] and muscle [2] are such examples, and even bone tissue [3] exists in an aligned manner as well. Aligned structures in tissues serve many purposes, providing physical strength and unique functions. Moreover, it is well known that providing micro- to nanoscale aligned topographic structures and physical strength, as in vivo, can enhance the activity of the cells grown above. The aligned structure makes cells elongate in a certain direction, which leads to genes or signaling pathways activation of cell proliferation or adhesion [4]. Previous studies reported that the alignment of surface topography can also have synergetic effects with the physicochemical properties of surface materials to promote osteogenic differentiation of cells, which can be considered an appropriate strategy to adapt in many tissue engineering examples [5-8]. 
The importance of alveolar bone regeneration is rising because it is one of the critical elements in dental implant treatment. Dental implants can serve an excellent masticating function and have many advantages leading to patient satisfaction when compared to conventional methods such as dentures. Nevertheless, post-surgery failures are constantly reported. If a tooth is lost, the surrounding bones decrease in volume and density. This results in vulnerability of the implant site, which is not a rare case $[9,10]$.

Thus, bone regeneration is essential in dental implant surgery. The bone graft material used for this purpose is bioceramic and can promote bone regeneration, and hydroxyapatitebased synthetic or xenograft product is commonly used [11-13].

Usually in powder form and having an artificial or natural origin, hydroxyapatitebased bone graft material has biocompatibility, biochemical similarity, osteoconductive and osteointegrating nature [14-20]. Xenograft materials or products such as Bio-Oss ${ }^{\circledR}$ showed osteointegration effects from in vivo tests. However, bone graft material or bioceramics themselves are brittle, have low impact resistance and relatively low tensile strengths, thus are hard to apply at the load bearing sites without additional solution [21]. Additionally, the invasion of connective tissues and cells into defects during the healing process is a major problem. When bioceramics are applied without any further treatment, little or no sign of bone healing or ingrowth of connective tissues are observed in the defect [22] or loss of original graft volume [23], resulting in delayed bone fusion or immature ossified condition $[23,24]$.

The guided bone regeneration (GBR) concept can be a solution. GBR is the method to isolate bone graft implant sites and gum tissue by placing a physical, biocompatible barrier between the sites $[25,26]$. The purpose of this strategy is to prevent invasion of nearby connective tissues and allow bone tissue-dominated regeneration. In many cases, it has been reported that the barrier is effective using only a bone graft material. Nevertheless, the solvent cast film-type polymer barrier still has some room for improvement since it is porous but does not have much surface area, brittle and inflexible without cytotoxic plasticizer [27] leading to less binding site [28], little or minimum growth and proliferation enhancement [29] to bone progenitor cells growing above. A fabricating method that can provide a polymer membrane with a high surface area and binding site and enhance cell growth would be suitable for the purpose.

Electrospinning presents some solutions to overcome the disadvantages of GBR films. It is a popular, relatively simple method to produce nano- to micro-diameter fiber mats that have a high surface area and controllable porosity due to a networked structure that also provides many binding sites to cells, including osteogenic sites. A simple change in the collector can also provide an aligned, oriented surface of nanofibers, such as in vivo tissue structures; the biodegradability depends on polymer variation [30-33]. By simply including bioceramics with sub/nanosized particles in a polymer solution, biochemically osteo-similar fibers can be produced that can target synergetic effects that might contribute to the osteogenic differentiation signaling pathway of mesenchymal stem cells [34,35]. FDA-approved poly( $\varepsilon$-caprolactone) can be the right polymer for fabricating GBR barriers, having many attractive features, such as biocompatibility, biodegradability, and low pricing, compared to other well-used polymers, such as poly(lactic acid) (PLA) or poly(lactic-coglycolic acid) (PLGA) [32,33].

In advance of previous reports that included hydroxyapatite (HA)-based bone graft material in electrospun mats, xenograft equine bone-derived nanohydroxyapatite (EBNH) was selected for this study. EBNH is produced by sintering equine bone at a high temperature, which is free of an immune response, infection, and bovine prion-associated disease when compared to conventional bovine xenograft bone graft materials [36] and has advantages such as biocompatibility and osteogenic activity promotion [37]. 
In this study, we produced aligned, EBNH-incorporated electrospun PCL-guided bone regeneration barriers (EBNH-RBs), which are biocompatible and biochemically similar to natural bone tissue. Finally, dental pulp-originated mesenchymal stem cells (DPSCs), which have multipotency and are capable of differentiating into dental tissues, including alveolar bone $[38,39]$, were cultured on the scaffold in vitro to determine its biocompatibility and osteogenic differentiation-promoting abilities on osteogenic cells. (Figure 1).

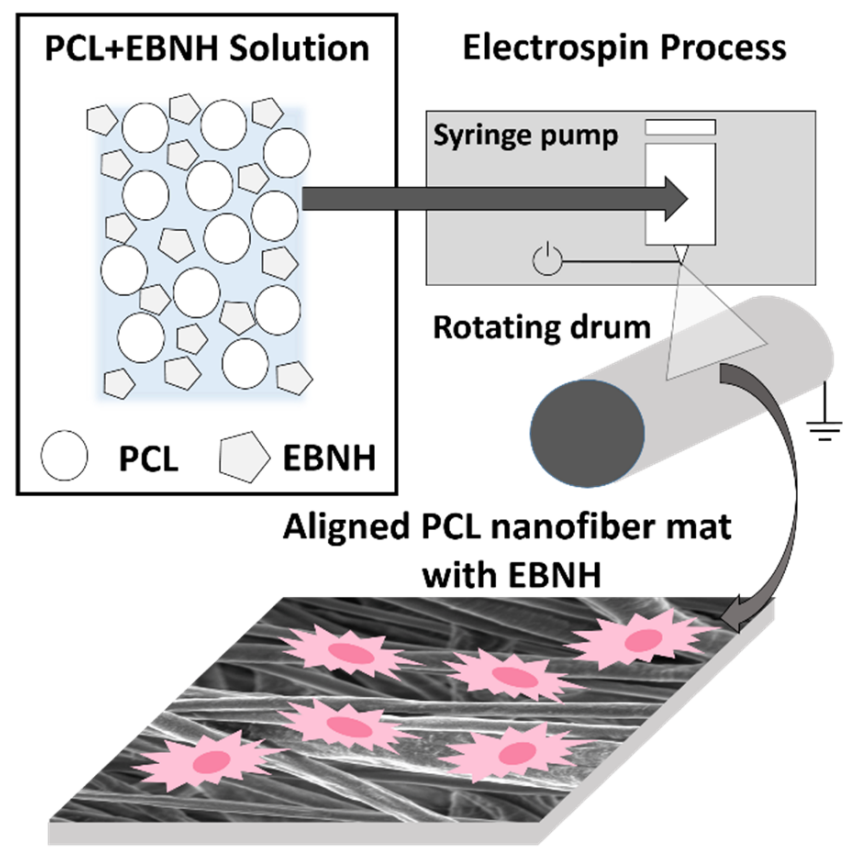

Dental pulp stem cells (DPSCs)

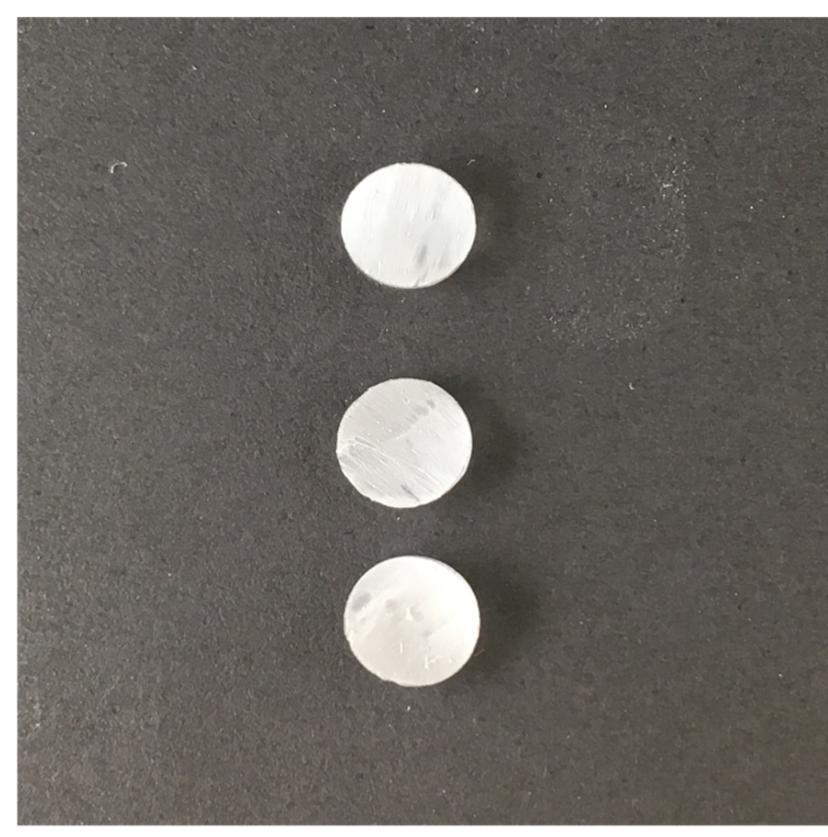

EBNH-RBs

Figure 1. Overall scheme of the research. Abbreviations: PCL, poly( $\varepsilon$-caprolactone), EBNH, equine bone-derived nanohydroxyapatite.

The objectives of this study are (1) to fabricate novel, aligned bone generation barrier with EBNH and (2) to enhance osteogenic differentiation of dental pulp stem cells by synergistic effects of fiber alignment and EBNH.

\section{Materials and Methods}

\subsection{Materials}

PCL (Mw 80,000), nHA, and Alizarin red staining agent (Aldrich, Gillingham, UK) were purchased from Sigma-Aldrich. WST-1 solution was purchased from Goma Biotech. Chloroform and dimethylformamide (Daejung, Gyeonggi-do, Korea) were purchased from Duksan. Culture media, antibiotics, fetal bovine serum (FBS), and Dulbecco's phosphatebuffered saline (DPBS) (Welgene, Daegu, Korea) were purchased from Welgene. Dental pulp stem cells were kindly provided by the School of Dentistry, Seoul National University. Polyclonal anti-human osteopontin goat $\operatorname{IgG}$, anti-goat IgG fluorescein isothiocyanate (FITC)-conjugated, tetramethylrhodamine (TRITC)-conjugated phalloidin, and 4',6diamidino-2-phenylindole (DAPI) (R\&D systems, Minneapolis, MN, USA) were purchased from R\&D Systems. Alexa Fluor ${ }^{\circledR} 594$ (Thermo Fisher, Frederick, MD, USA) was purchased from Thermo Fisher.

Equine bone-derived nanohydroxyapatite (EBNH) was prepared from previous methods as follows: washed, $\mathrm{H}_{2} \mathrm{O}_{2}$-pretreated horse bone was sintered at $1300{ }^{\circ} \mathrm{C}$ in a furnace to remove organic components and possible contaminants, and then the remaining minerals were processed with a blade grinder and high-power ball mill to produce finer particles and sieved for even size distribution [33]. 


\subsection{Electrospinning Process}

A $10 \%$ PCL $(w / v)$ solution was prepared by chloroform and DMF as the solvent. For each group, EBNH and nHA were equivalently mixed into PCL solution following $10 \mathrm{~s}$ of 3 sets of sonication. The composition of each group is listed in Table 1.

Table 1. Composition of experimental groups and control.

\begin{tabular}{ccc}
\hline Name & Bioceramic $(\mathbf{m g})$ & PCL $(\mathrm{g})$ \\
\hline Control (PCL) & $0 \mathrm{mg}$ & $1 \mathrm{~g}$ \\
nHA & $10 \mathrm{mg}(\mathrm{nHA})$ & $1 \mathrm{~g}$ \\
$\mathbf{1 \%}$ EBNH & $10 \mathrm{mg}(\mathrm{EBNH})$ & $1 \mathrm{~g}$ \\
$\mathbf{1 0} \%$ EBNH & $100 \mathrm{mg}(\mathrm{EBNH})$ & $1 \mathrm{~g}$ \\
\hline
\end{tabular}

A continuous flow syringe pump (KD scientific KDS270, Holliston, MA, USA) was used to feed PCL solution at a constant rate. Nanofibers were collected on a metal collector at a $100 \mathrm{~mm}$ nozzle to ground metal collector distance, $23^{\circ} \mathrm{C}, 30$ to $40 \%$ moisture, 22-gauge nozzle, $18 \mathrm{kV}$ voltage, $0 \mathrm{~mA}$ current, and syringe pump rate of $0.6 \mathrm{~mL} / \mathrm{h}$ for $30 \mathrm{~min}$. All solutions were sonicated for 3 sets of $10 \mathrm{~s}$ to disperse the solute evenly. The aligned group was collected under the same conditions, except for a voltage of $12 \mathrm{kV}$ and grounded rotating drum collector spinning at 3000 RPM considering the fiber collection rate and alignment. The remaining solvent was removed by ventilation under a fume hood overnight. The resulting fiber mat was punched on the PDMS layer to make an in vitro sample and stored for further use.

\subsection{Fiber Characterization}

\subsubsection{Scanning Electronic Microscopy (SEM)}

The sample was placed in a $60^{\circ} \mathrm{C}$ dry oven for at least one day to remove the remaining solvent and moisture, sputter coated, and placed on a grid, and images were taken using a field emission scanning electron microscope (Zeiss SUPRA 55 VP, Oberkochen, Germany).

\subsubsection{Fiber Orientation Analysis}

The fiber orientation of the samples was examined by the OrientationJ plugin of ImageJ $1.51 \mathrm{k}$. Eight random sites were selected from the SEM image of each sample.

\subsubsection{X-ray Diffractometry (XRD)}

Four variations of the sample (Control, $1 \% \mathrm{nHA}, 1 \% \mathrm{EBNH}, 10 \% \mathrm{EBNH}$ ) were tested using an X-ray diffraction instrument (Bruker D8 Advance, Karlsruhe, Germany) in settings of $\mathrm{Cu}-\mathrm{K} 3 \mathrm{~kW}$.

\subsection{In Vitro Experiments}

Based on a literature study, four in vitro groups were selected: PCL, nHA, 1\% EBNH, and $10 \% \mathrm{EBNH}$, which all have aligned fiber topography. Before seeding, EBNH-RB were sterilized with $70 \%$ ethanol and then washed with DPBS three times. Then, the scaffolds were exposed to UV light for $30 \mathrm{~min}$ to remove any possible contaminants. Sterilized scaffolds were put into well plates, and the cells were pre-seeded for at least $1 \mathrm{~h}$ to prevent unwanted growth on the TCPS. Then, $\alpha$-MEM with $10 \%$ fetal bovine serum and $0.5 \%$ antibiotics was supplied and changed on a regular schedule. Osteogenic media was supplied after cell attachment in the differentiation assay, which was composed of $0.1 \mu \mathrm{M}$ dexamethasone, $10 \mu \mathrm{M} \beta$-glycerophosphate, and $100 \mu \mathrm{M}$ ascorbic acid added to the proliferation media. 


\subsubsection{Cell Viability Assay}

To examine the viability of EBNH-RBs, $1 \times 10^{3}$ cells/well were seeded onto $6 \mathrm{~mm}$ samples in 96-well culture plates $(n=5)$. For the procedure, WST-1 agent was diluted in proliferation media as described in the manufacturer's instructions. Each well was aspirated and washed three times with DPBS. Two hundred microliters of WST solution was placed into each well, and then the plate was cultured at $37^{\circ} \mathrm{C}$ for an hour. Then, $100 \mu \mathrm{L}$ of solution from each well was transferred to a new 96-well plate and measured in an ELISA machine at $450 \mathrm{~nm}$ wavelength. The resulting data were converted as percentages compared to the control (PCL Aligned).

\subsubsection{Alizarin Red Assay}

To examine the mineral deposition of cells on EBNH-RBs due to osteogenic differentiation, $3 \times 10^{3}$ cells / well were seeded onto 96-well culture plates $(n=7)$ supplied with osteogenic media. After a pre-determined period, each well was aspirated and washed three times with DPBS and then fixed with $4 \%$ paraformaldehyde solution. Then, each well was washed with DPBS three times. Then, $200 \mu \mathrm{L}$ of the Alizarin red solution was put into each well, and the plate was cultured at room temperature for $1 \mathrm{~h}$. Next, solution from each well was aspirated, and $200 \mu \mathrm{L}$ of destaining solution was put into each well and cultured at room temperature for $1 \mathrm{~h}$ to harvest the dyes absorbed by the mineralized tissues. One hundred microliters of the destained fluid was transferred to a new 96-well plate and measured by an ELISA at $570 \mathrm{~nm}$ wavelength.

\subsubsection{Immunocytochemistry}

To determine the expression of osteogenic markers, $3 \times 10^{4}$ passage 5 dental pulp cells were seeded onto $24 \mathrm{~mm}$ diameter nanofiber-PDMS scaffolds in 24-well plates $(n=5)$, and other procedures, such as scaffold sterilization and fixation, were performed as described above.

After fixation and washing three times with $0.01 \%$ Tween 20-PBS solution (PBST), $1 \%$ Triton $X$ solution was added to each well for $15 \mathrm{~min}$ to permeabilize. After washing three times with PBST, $1 \%$ bovine serum albumin (BSA) solution was added to each well and incubated at room temperature for $1 \mathrm{~h}$ for blocking. Appropriate concentrations of primary antibody (polyclonal anti-human osteopontin goat IgG, R\&D Systems AF1433), secondary antibody (anti-goat IgG fluorescein isothiocyanate (FITC)-conjugated, tetramethylrhodamine (TRITC)-conjugated phalloidin), Alexa Fluor ${ }^{\circledR} 594$ and DAPI solution were continuously added for $1 \mathrm{~h}$, except $5 \mathrm{~min}$ for DAPI. Each sample was washed three times with PBST between and after treatment. All scaffolds were mounted on a cover glass after staining was performed and imaged with a high-resolution fluorescence microscope (Nicon N-Storm, Tokyo, Japan).

The intensity of each image was analyzed with the ROI manager tool in ImageJ, randomly selecting five 50,000 pixel-sized square image sites.

\subsection{Statistical Analysis}

The statistical significance of quantitative data was analyzed by performing Duncan's multiple range test and two-way ANOVA between each group. At $p<0.05$, differences between groups were considered to be statistically significant.

\section{Results and Discussion}

\subsection{Characterization of EBNH-RBS}

As shown in Figure 2, the addition of EBNH and nHA changed the individual fibers on a rougher surface but nevertheless maintained sub-micro- to nanodiameters and unique microstructures (Figure 2a). In fiber orientation analysis by OrientationJ, aligned scaffolds showed a distribution of orientations concentrated over 1000 in certain degree orientations, while random patterned scaffolds showed a distribution of orientations under 1000 with varying degree orientations (Figure $2 b$ ). 
a. b.
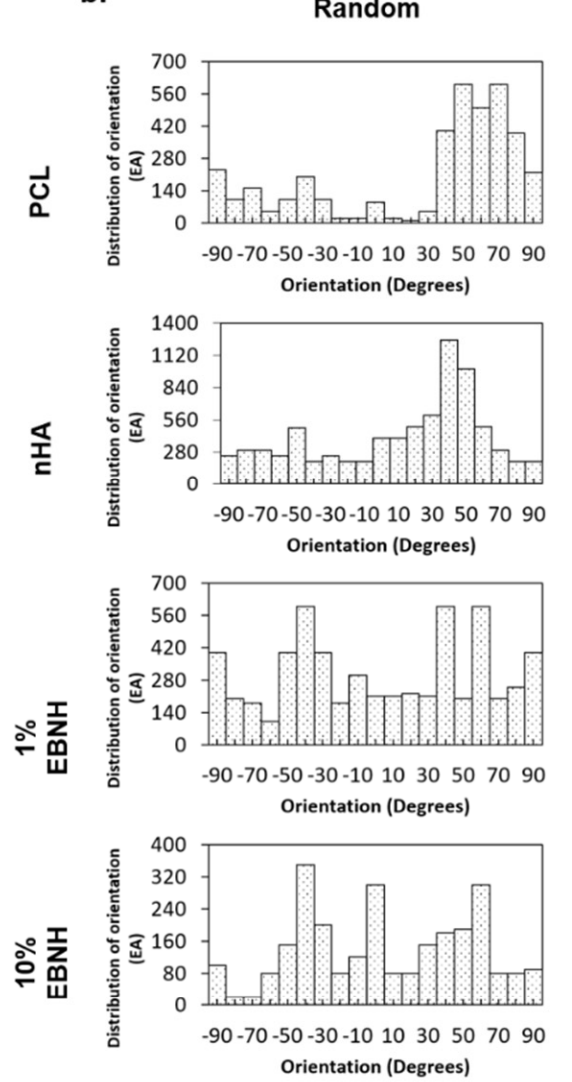

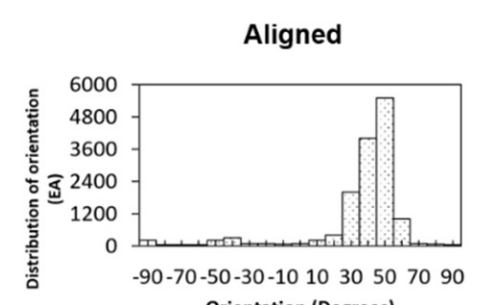

Orientation (Degrees)

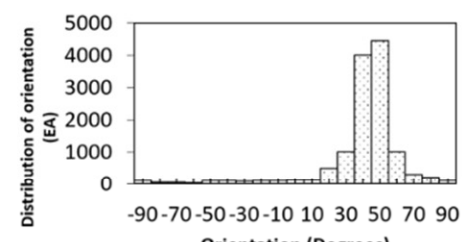
Orientation (Degrees)
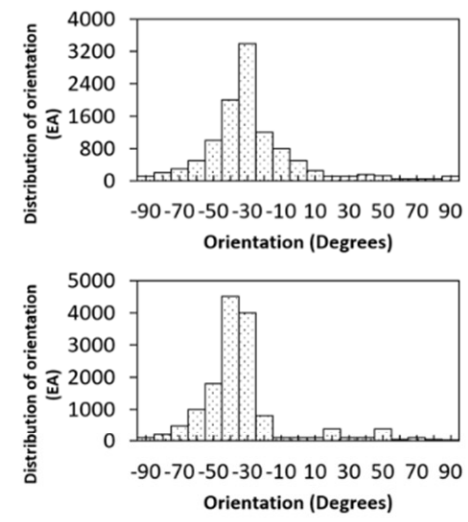

c.

d.
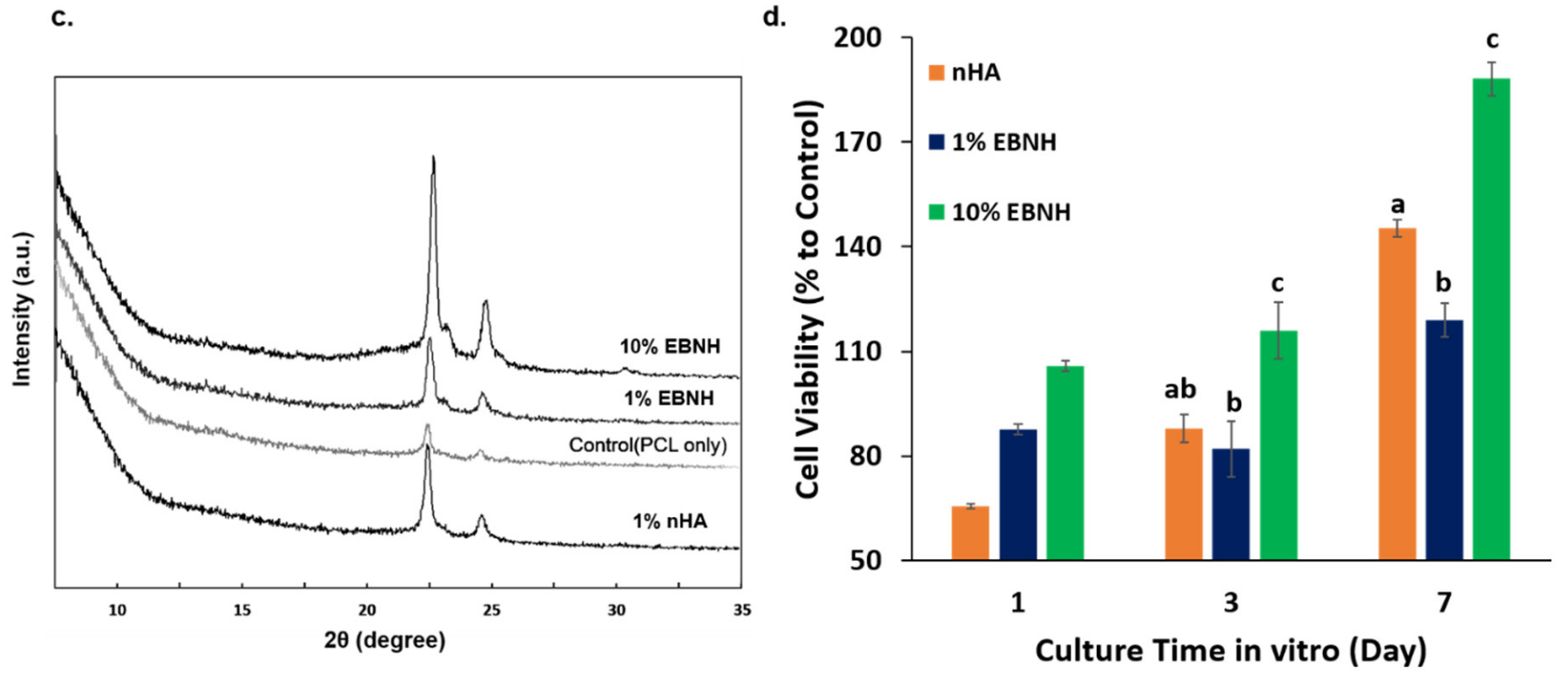

Figure 2. Characteristics of EBNH-RBs. (a) FESEM images of the fiber. (b) Distribution of fiber alignment. Aligned EBNHRBs showed at least 3000 to 4000 distributions in certain alignments compared to random EBNH-RBs. (c) XRD peaks of electrospun nanofibers. (d) WST-1 results of cells cultured on EBNH-RBs by day. EBNH-RBs maintained the peaks of EBNH or hydroxyapatite after electrospinning, and viability increased by almost two-fold in the day $710 \%$ EBNH group. (Having non-identical letters, such as a and $b$, means that the groups have statistically significant differences at $p<0.05(n=5)$. 
Almost every EBNH-RB showed HA with a similar XRD peak at $2 \theta=22.5$ and 25 except for the PCL-only group. These results show that EBNH maintained HA-like chemical properties even after being electrospun with PCL (Figure 2c). These features may have interacted with the alignment of fiber to induce synergetic activity for the mesenchymal stem cells, which give oriented microstructure and biochemical properties to EBNH-RBs making it similar to in vivo osteogenic tissue. It is well known that cells can change morphology by the cultured surface, and nanofibers are one of the examples. Cell lines grown on aligned fibers tended to have spindle-like cell morphology even at the single-cell level. [39]. Adding biominerals such as HA causes the aligned fiber structure with an encapsulated or coated structure to resemble the microstructure of the bone or dentin [40]. There is a report that aligned nanofibers with HA can induce osteogenic differentiation even without any soluble factors [41], which may explain the cell behavior of DPSCs cultured on EBNH-RBs.

\subsection{Cell Viability}

In the WST results, groups with a higher ratio of bioceramics showed a larger percentage of cell viability in vitro. The $10 \%$ EBNH group had a significantly larger percentage of viability than the nHA and 1\% EBNH groups on day 3 and day 7. Especially on day 7, the viability of the $10 \%$ EBNH group increased almost two-fold (Figure $2 \mathrm{~d}$ ).

Although PCL itself is a biocompatible material, a rise in the EBNH ratio resulted in a significant increase in viability. This can be evidence that the alignment of PCL fibers and bioceramics may have some synergistic effect, enhancing cell adhesion, viability, and other related features. An increase in EBNH concentration could have induced the microstructure to have more in vivo-like properties along with alignment, therefore increasing the affinity and viability of the EBNH-RBs to DPSCs. The addition of HA can also decrease crystallinity by disrupting the growth of the crystal surface, and decreased crystallinity leads to increased cell viability [42]. EBNH may disrupt crystal surface growth more than nHA, especially at high concentrations, which leads to higher DPSC viability. Additionally, the fiber surface in the rough state could be an outcome of surface disruption.

\subsection{Osteogenic Differentiation}

Groups with aligned fiber structures and bioceramics showed stronger figment colors than the controls, and 10\% EBNH showed a significantly larger value than the control in week 4 (Figure 3a).

Immunocytochemistry results show osteogenic marker protein osteopontin (OPN) present in the scaffold after differentiation, presenting aligned patterns and the actin cytoskeleton in bright red while nuclei of DPSCs are present in a blue color stain. (Figure 3b).

Osteogenic marker protein expression showed the osteogenic differentiation enhancing effect of EBNH more clearly. The $1 \%$ and $10 \%$ EBNH group showed significantly higher OPN expression than the nHA group, and 10\% EBNH group showed significantly higher OPN expression even when compared to control. This is quite controversial from the week 4 Alizarin red result. Thus, at least for OPN expression, EBNH is better than nHA and can enhance overall features, including cell viability, mineral deposition, and osteogenic marker expression, in a higher ratio than nHA.

Previous studies have noted that aligned structures can enhance cell adhesion to the surface, and aligned structures can have a synergistic effect with the physicochemical properties of the material. PCL and EBNH, which are the two main components in this study, showed excellent incorporation into each other and maintained unique chemical properties. While the microstructure and biochemical composition of EBNH-RBs is similar to the in vivo minimal unit of bone or osteon, the distribution of the graft material in the fibers may have decreased surface crystallinity and increased cell-surface affinity, leading to higher OPN expression, as explained above in the viability data. EBNH-RBs are expected to enhance the osteogenic differentiation of mesenchymal cells by synergistic effects between 
EBNH and the aligned structure, which is expected to serve as an excellent barrier for alveolar bone-guided regeneration, while the application to bone defects in another defect makes the platform versatile.

a.

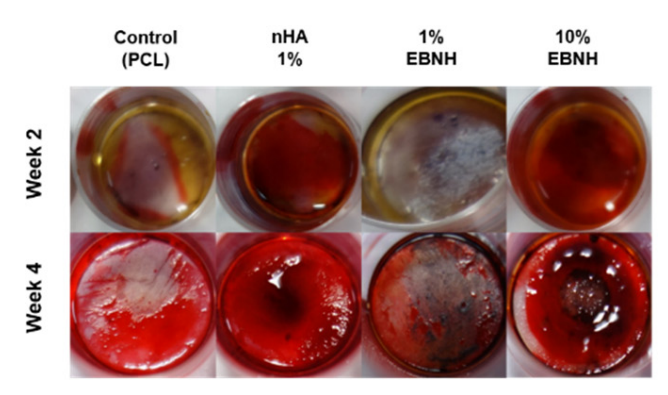

b.
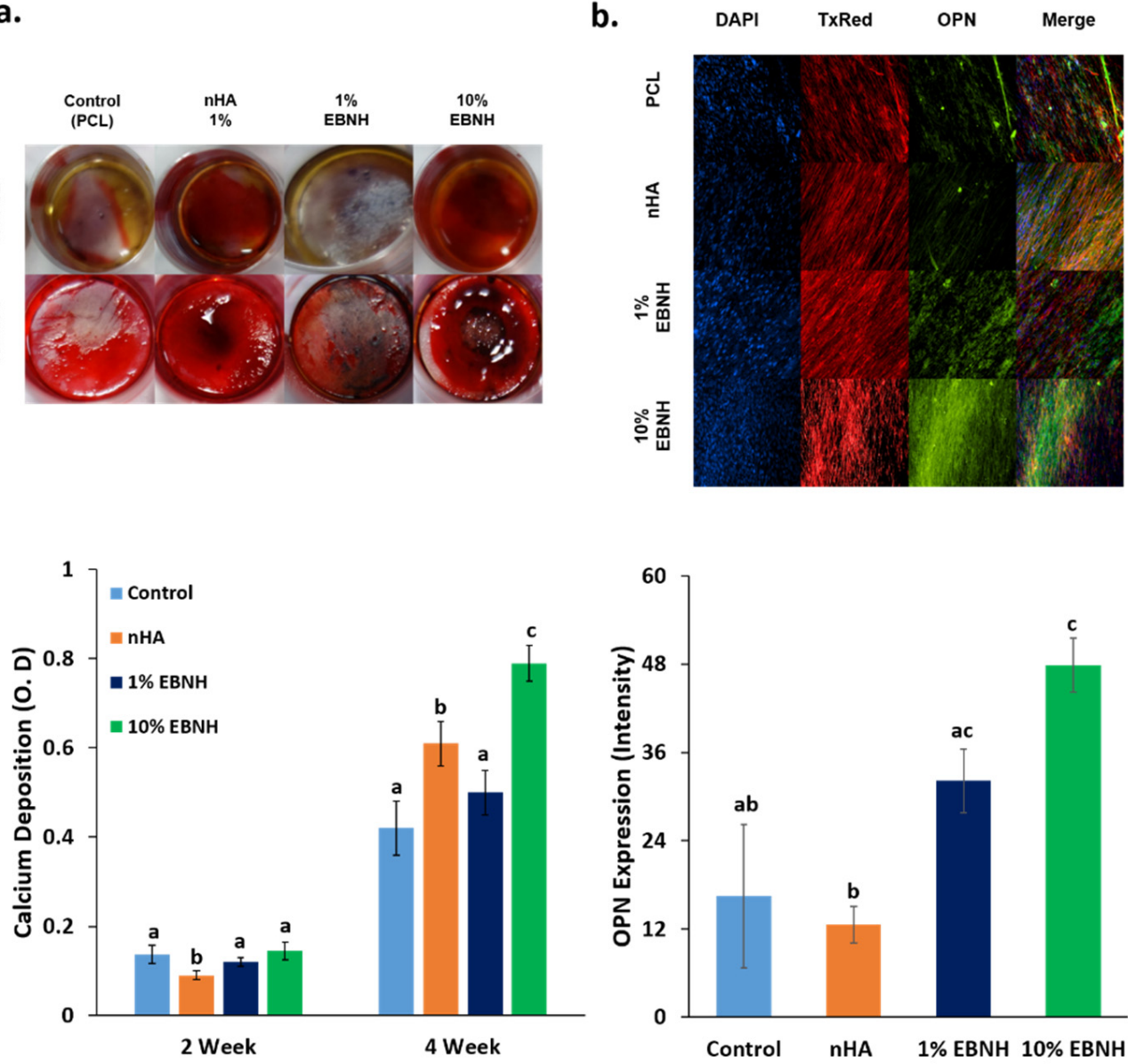

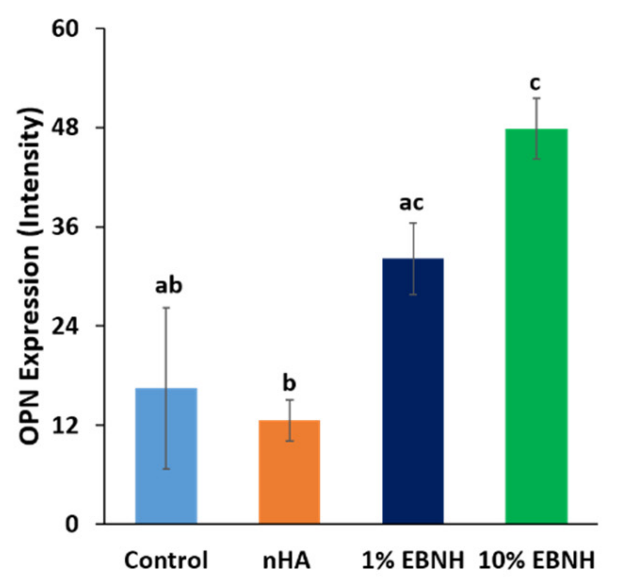

Figure 3. Differentiation of cells on EBNH-RBs. (a) Alizarin red staining images and destain results of dental pulp stem cells on nanofiber scaffolds by week. (b) Immunocytochemistry (ICC) fluorescent image of dental pulp stem cells 4 weeks after differentiation. DAPI stained the cell nucleus, TxRed (Alexa 594) stained the actin cytoskeleton, and FITC-TRITC conjugated phalloidin stained OPN. (Having non-identical letters, such as $a$ and $b$, means that the groups have statistically significant differences at $p<0.05(n=5)$. Groups with common letters to others, such as a and ab, were not significantly different. While the $10 \%$ EBNH groups had a significantly high or high tendency in the differentiation assays, it is remarkable that the 1\% EBNH group had less calcium deposition but expressed higher levels of OPN than the nHA group.

\section{Conclusions}

A novel, aligned bone generation barrier with EBNH (EBNH-RB) was fabricated by electrospinning, and the barrier enhanced osteogenic differentiation of mesenchymal stem cells by synergistic effects of fiber alignment and EBNH. The results suggest that alignment of PCL and EBNH has a synergistic effect in enhancing the growth, viability, and overall osteogenic differentiation of mesenchymal stem cells, especially in the PCL with 10\% EBNH group (Figure 4). EBNH-RB would be excellent platform for promoting bone regeneration effect on dental implant site as guided bone regeneration barrier, and growth factors or other bone regeneration promoting elements can be adapted to the barrier as well for further in vivo experiment and actual therapeutic application. 

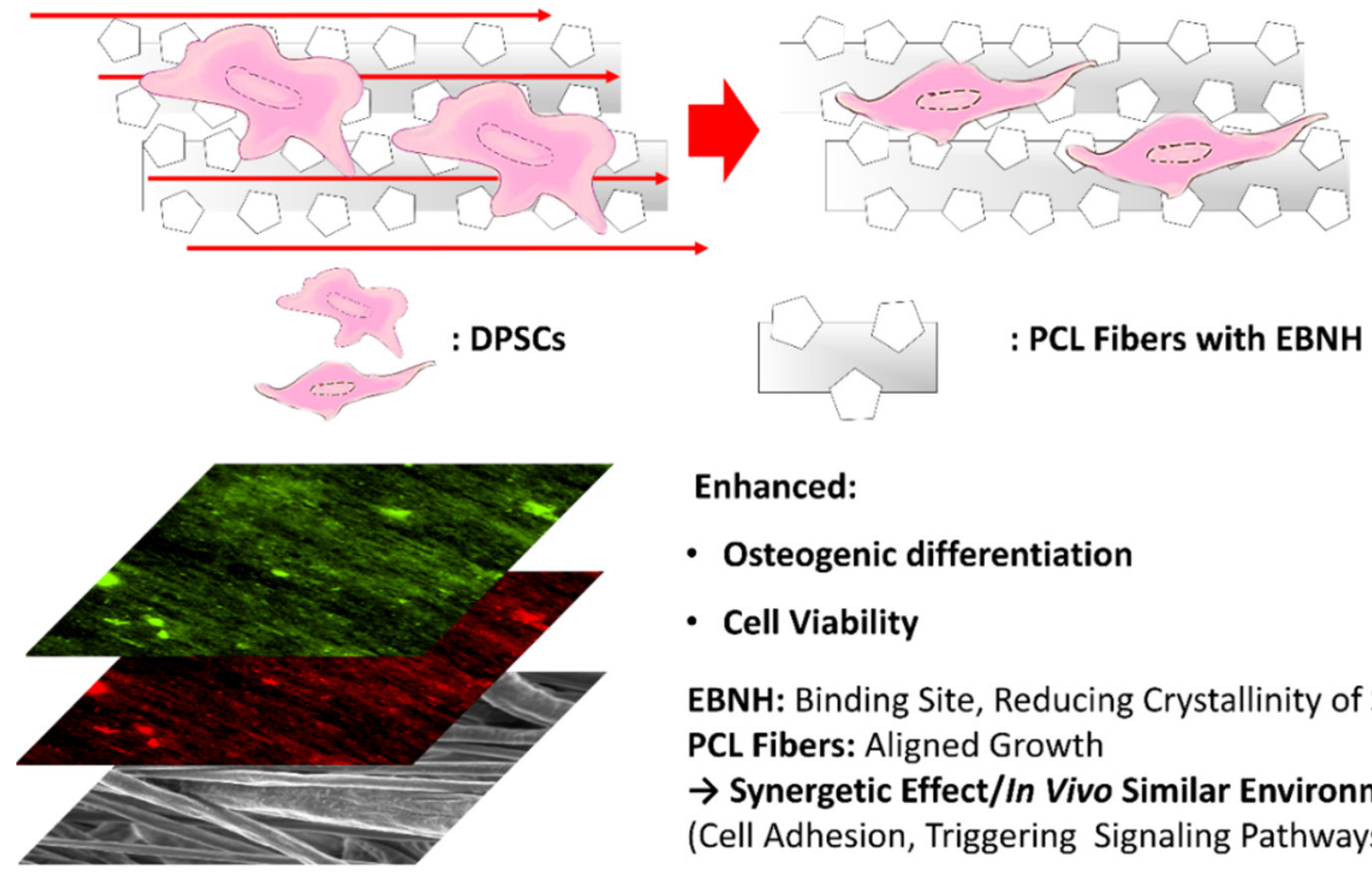

\section{Enhanced:}

- Osteogenic differentiation

- Cell Viability

EBNH: Binding Site, Reducing Crystallinity of Surface PCL Fibers: Aligned Growth $\rightarrow$ Synergetic Effect/In Vivo Similar Environment (Cell Adhesion, Triggering Signaling Pathways, etc.)

Figure 4. Overall summary of the study. EBNH-RBs enhanced osteogenic differentiation and cell viability, possibly by the synergetic effect of EBNH, reducing crystallinity and alignment of PCL nanofibers combined with EBNH to induce a similar in vivo environment.

Author Contributions: Conceptualization, H.S. (Hoon Seonwoo), J.W.L. and J.H.C.; methodology, J.W.L. and J.H.C.; validation, J.W.L., M.C.L., H.S. (Hyunmok Son), S.P., H.B.K. and J.E.K.; formal analysis, J.W.L.; investigation, J.W.L.; resources, K.J.J., Y.H.C.; data curation, J.W.L. and K.J.J.; writing—original draft preparation, J.W.L.; writing—review and editing, J.W.L., M.C.L. and J.H.C.; visualization, J.W.L.; supervision, H.S. (Hoon Seonwoo), M.C.L. and J.H.C.; project administration, H.S. (Hoon Seonwoo), J.W.L. and J.H.C.; funding acquisition, H.S. (Hoon Seonwoo), Y.H.C. and J.H.C. All authors have read and agreed to the published version of the manuscript.

Funding: This research received none of any other external funding than NRF-2020R1F1A1067439 and KETEP \& MOTIE 20194210100230.

Institutional Review Board Statement: Not applicable.

Informed Consent Statement: Not applicable.

Data Availability Statement: All the experimental data herein presented are made available upon request to the corresponding author.

Acknowledgments: This work was supported by the National Research Foundation of Korea (NRF) grant funded by the Korea government (MSIT) (NRF-2020R1F1A1067439) and Korea Institute of Energy Technology Evaluation and Planning (KETEP) and the Ministry of Trade, Industry \& Energy (MOTIE) of the Republic of Korea (20194210100230). EBNH used in this study was kindly provided by Kyoung-Je Jang (Gyoungsang National University).

Conflicts of Interest: The authors have no conflicting financial or other interests. 


\section{References}

1. Snedeker, J.G.; Follen, J. Tendon injury and repair-A perspective on the basic mechanisms of tendon disease and future clinical therapy. Acta Biomater. 2017, 63, 18-36. [CrossRef] [PubMed]

2. Bian, W.; Bursac, N. Engineered skeletal muscle tissue networks with controllable architecture. Biomaterials 2009, 30, 1401-1412. [CrossRef] [PubMed]

3. Du, Y.; Guo, J.L.; Wang, J.; Mikos, A.G.; Zhang, S. Hierarchically designed bone scaffolds: From internal cues to external stimuli. Biomaterials 2019, 218, 119334. [CrossRef] [PubMed]

4. Newman, P.; Galenano-Niño, J.L.; Graney, P.; Razal, J.M.; Minett, A.I.; Ribas, J.; Ovalle-Robles, R.; Biro, M.; Zreiqat, H. Relationship between nanotopographical alignment and stem cell fate with live imaging and shape analysis. Sci. Rep. 2016, 6, 37909. [CrossRef]

5. Cristofaro, F.; Gigli, M.; Bloise, N.; Chen, H.; Bruni, G.; Munari, A.; Moroni, L.; Lotti, N.; Visai, L. Influence of the nanofiber chemistry and orientation of biodegradable poly(butylene succinate)-based scaffolds on osteoblast differentiation for bone tissue regeneration. Nanoscale 2018, 10, 8689-8703. [CrossRef]

6. Chew, S.Y.; Mi, R.; Hoke, A.; Leong, K.W. Aligned protein-Polymer composite fibers enhance nerve regeneration: A potential tissue-engineering platform. Adv. Funct. Mater. 2007, 17, 1288-1296. [CrossRef]

7. Kai, D.; Prabhakaran, M.P.; Jin, G.; Ramakrishna, S. Guided orientation of cardiomyocytes on electrospun aligned nanofibers for cardiac tissue engineering. J. Biomed. Mater. Res. Part B Appl. Biomater. 2011, 98, 379-386. [CrossRef]

8. Kishore, V.; Bullock, W.; Sun, X.; Van Dyke, W.S.; Akkus, O. Tenogenic differentiation of human MSCs induced by the topography of electrochemically aligned collagen threads. Biomaterials 2012, 33, 2137-2144. [CrossRef]

9. Bodic, F.; Hamel, L.; Lerouxel, E.; Baslé, M.F.; Chappard, D. Bone loss and teeth. Jt. Bone Spine 2005, 72, 215-221. [CrossRef]

10. Chrcanovic, B.R.; Albrektsson, T.; Wennerberg, A. Bone quality and quantity and dental implant failure: A systematic review and meta-analysis. Int. J. Prosthodont. 2017, 30, 219-237. [CrossRef]

11. Zafar, M.S.; Farooq, I.; Awais, M.; Najeeb, S.; Khurshid, Z.; Zohaib, S. Bioactive surface coatings for enhancing osseointegration of dental implants. In Biomedical, Therapeutic and Clinical Applications of Bioactive Glasse; Woodhead Publishing: Cambridge, UK, 2019; pp. 313-329.

12. Najeeb, S.; Khurshid, Z.; Zohaib, S.; Zafar, M.S. Bioactivity and osseointegration of PEEK are inferior to those of titanium: A systematic review. J. Oral Implantol. 2016, 42, 512-516. [CrossRef] [PubMed]

13. Zafar, M.S.; Fareed, M.A.; Riaz, S.; Latif, M.; Habib, S.R.; Khurshid, Z. Customized therapeutic surface coatings for dental implants. Coatings 2020, 10, 568. [CrossRef]

14. Bow, A.; Anderson, D.E.; Dhar, M. Commercially available bone graft substitutes: The impact of origin and processing on graft functionality. Drug Metab. Rev. 2019, 51, 533-544. [CrossRef] [PubMed]

15. Damien, C.J.; Parsons, J.R. Bone graft and bone graft substitutes: A review of current technology and applications. J. Appl. Biomater. 1991, 2, 187-208. [CrossRef]

16. Dutta, S.R.; Passi, D.; Singh, P.; Bhuibhar, A. Ceramic and non-ceramic hydroxyapatite as a bone graft material: A brief review. Ir. J. Med Sci. 2015, 184, 101-106. [CrossRef]

17. Sohn, H.-S.; Oh, J.-K. Review of bone graft and bone substitutes with an emphasis on fracture surgeries. Biomater. Res. 2019, 23, 1-7. [CrossRef]

18. Broggini, N.; Bosshardt, D.D.; Jensen, S.S.; Bornstein, M.M.; Wang, C.-C.; Buser, D. Bone healing around nanocrystalline hydroxyapatite, deproteinized bovine bone mineral, biphasic calcium phosphate, and autogenous bone in mandibular bone defects. J. Biomed. Mater. Res. Part B Appl. Biomater. 2014, 103, 1478-1487. [CrossRef]

19. Finkemeier, C.G. Bone-Grafting and bone-graft subtitutes. J. Bone Jt. Surg. Am. Vol. 2002, 84, 454-464. [CrossRef]

20. Berglundh, T.; Lindhe, J. Healing around implants placed in bone defects treated with Bio-Oss®. An experimental study in the dog. Clin. Oral Implant. Res. 1997, 8, 117-124. [CrossRef]

21. Charalambous, C.P. Calcium phosphate ceramics as hard tissue prosthetics. Classic Papers in Orthopaedics; Springer: London, UK, 2013; Volume 157, pp. 419-421. [CrossRef]

22. Dahlin, C.; Linde, A.; Gottlow, J.; Nyman, S. Healing of bone defects by guided tissue regeneration. Plast. Reconstr. Surg. 1988, 81, 672-676. [CrossRef]

23. Nascimento, R.D.; Cardoso, P.E.; De Marco, A.C.; de Lima, L.A.P.A.; Jardini, M.A.N. Influence of osteopenia in autogenous bone graft healing with or without expanded polytetrafluoroethylene membranes: histologic and histomorphometric study in rats. Int. J. Oral Maxillofac. Implants 2009, 24, 1074-1082. [PubMed]

24. Ahn, Y.S.; Kim, S.G.; Kim, C.S.; Oh, J.S.; Lim, S.C. Effect of guided bone regeneration with or without pericardium bioabsorbable membrane on bone formation. Oral Surg. Oral Med. Oral Pathol. Oral Radiol. 2012, 114, 126-131. [CrossRef] [PubMed]

25. Schenk, R.K.; Buser, D.; Hardwick, W.R.; Dahlin, C. Healing Pattern of Bone Regeneration in Membrane-Protected Defects: A Histologic Study in the Canine Mandible. Int. J. Oral Maxillofac Implants 1994, 9, 13-29. [PubMed]

26. Kay, S.A.; Wisner-Lynch, L.; Marxer, M.; Lynch, S.E. Guided bone regeneration: Integration of a resorbable membrane and a bone graft material. Pract. Periodontics Aesthet. Dent. PPAD 1997, 9, 185-194.

27. Ghosal, K.; Chandra, A.; Praveen, G.; Snigdha, S.; Roy, S.; Agatemor, C.; Thomas, S.; Provaznik, I. Electrospinning over Solvent Casting: Tuning of Mechanical Properties of Membranes. Sci. Rep. 2018, 8, 1-9. [CrossRef]

28. Bagher, Z.; Ebrahimi-Barough, S.; Azami, M.; Safa, M.; Joghataei, M.T. Cellular activity of Wharton's Jelly-derived mesenchymal stem cells on electrospun fibrous and solvent-cast film scaffolds. J. Biomed. Mater. Res. Part A 2015, 104, 218-226. [CrossRef] 
29. Ahmed, F.; Dutta, N.K.; Zannettino, A.; VanDyke, K.; Choudhury, N.R. Engineering interaction between bone marrow derived endothelial cells and electrospun surfaces for artificial vascular graft applications. Biomacromolecules 2014, 15, $1276-1287$. [CrossRef]

30. Doshi, J.; Reneker, D.H. Electrospinning process and applications of electrospun fibers. J. Electrost. 1995, 35, 151-160. [CrossRef]

31. Chen, X.; Fu, X.; Shi, J.G.; Wang, H. Regulation of the osteogenesis of pre-osteoblasts by spatial arrangement of electrospun nanofibers in two- and three-dimensional environments. Nanomed. Nanotechnol. Biol. Med. 2013, 9, 1283-1292. [CrossRef]

32. Kim, G.H. Electrospun PCL nanofibers with anisotropic mechanical properties as a biomedical scaffold. Biomed. Mater. 2008, 3, 025010. [CrossRef]

33. Ke, R.; Yi, W.; Tao, S.; Wen, Y.; Hongyu, Z. Electrospun PCL/gelatin composite nanofiber structures for effective guided bone regeneration membranes. Mater. Sci. Eng. C 2017, 78, 324-332. [CrossRef]

34. Chen, Y.; Mak, A.F.; Wang, M.; Li, J.; Wong, M. PLLA scaffolds with biomimetic apatite coating and biomimetic apatite/collagen composite coating to enhance osteoblast-like cells attachment and activity. Surf. Coat. Technol. 2006, 201, 575-580. [CrossRef]

35. Kharaziha, M.; Fathi, M.H.; Edris, H. Development of novel aligned nanofibrous composite membranes for guided bone regeneration. J. Mech. Behav. Biomed. Mater. 2013, 24, 9-20. [CrossRef] [PubMed]

36. Sogal, A.; Tofe, A.J. Risk assessment of bovine spongiform encephalopathy transmission through bone graft material derived from bovine bone used for dental applications. J. Periodontol. 1999, 70, 1053-1063. [CrossRef] [PubMed]

37. Jang, K.-J.; Cho, W.J.; Seonwoo, H.; Kim, J.; Lim, K.T.; Chung, P.-H.; Chung, J.H. Development and characterization of horse bone-derived natural calcium phosphate powders. J. Biosyst. Eng. 2014, 39, 122-133. [CrossRef]

38. Gronthos, S.; Brahim, J.; Li, W.; Fisher, L.W.; Cherman, N.; Boyde, A.; DenBesten, P.; Robey, P.G.; Shi, S. Stem cell properties of human dental pulp stem cells. J. Dent. Res. 2002, 81, 531-535. [CrossRef] [PubMed]

39. Arthur, A.; Rychkov, G.; Shi, S.; Koblar, S.A.; Gronthos, S. Adult human dental pulp stem cells differentiate toward functionally active neurons under appropriate environmental cues. Stem Cells 2008, 26, 1787-1795. [CrossRef]

40. Qi, Y.; Cheng, Z.; Ye, Z.; Zhu, H.; Aparicio, C. Bioinspired mineralization with hydroxyapatite and hierarchical naturally aligned nanofibrillar cellulose. ACS Appl. Mater. Interfaces 2019, 11, 27598-27604. [CrossRef]

41. Soheilmoghaddam, M.; Padmanabhan, H.; Cooper-White, J.J. Biomimetic cues from poly(lactic-co-glycolic acid)/hydroxyapatite nano-fibrous scaffolds drive osteogenic commitment in human mesenchymal stem cells in the absence of osteogenic factor supplements. Biomater. Sci. 2020, 8, 5677-5689. [CrossRef]

42. Neto, W.A.R.; Pereira, I.H.; Ayres, E.; De Paula, A.C.; Averous, L.; Góes, A.M.; Oréfice, R.L.; Bretas, R.E.S. Influence of the microstructure and mechanical strength of nanofibers of biodegradable polymers with hydroxyapatite in stem cells growth. Electrospinning, characterization and cell viability. Polym. Degrad. Stab. 2012, 97, 2037-2051. [CrossRef] 